\title{
Double-balloon enteroscopy following capsule endoscopy in the management of obscure gastrointestinal bleeding: Outcome of a combined approach
}

\author{
Patarapong Kamalaporn MD, Sarah Cho MD, Nancy Basset RN, Maria Cirocco RN, \\ Gary May MD, Paul Kortan MD, Gabor Kandel MD, Norman Marcon MD
}

P Kamalaporn, S Cho, N Basset, et al. Double-balloon enteroscopy following capsule endoscopy in the management of obscure gastrointestinal bleeding: Outcome of a combined approach. Can J Gastroenterol 2008;22(5):491-495.

BACKGROUND: There is no consensus on the relative accuracy of capsule endoscopy (CE) versus double-balloon enteroscopy (DBE) to investigate obscure gastrointestinal bleeding (GIB). CE is less invasive, but DBE more directly examines the small bowel, and allows tissue sampling plus therapeutic intervention.

OBJECTIVES: To evaluate the yield and outcome of DBE following $\mathrm{CE}$ in patients with obscure GIB.

METHODS: After DBE became readily available at the Centre for Therapeutic Endoscopy and Endoscopic Oncology (St Michael's Hospital, Toronto, Ontario), all patients with obscure GIB seen from December 2002 to June 2007 were evaluated identically, first with $\mathrm{CE}$, then with DBE (some with further interventions). Findings, adverse outcomes and interventions are reported.

RESULTS: Fifty-one patients ( 25 women) with a mean (range) age of 64.1 years (34 to 83 years) are reported. Eight patients underwent DBE twice, for a total of 59 DBEs. Fourteen patients had overt GIB and the median (range) number of red blood cell unit transfusions was 10 ( 0 to 100). The positive findings for each type of lesion were compared in these 51 patients: angiodysplasia (CE 64.7\% and DBE 61\%, $\mathrm{P}=0.3$ ), ulcers (CE 19.6\% and DBE 18.6\%, $\mathrm{P}=0.5$ ), bleeding lesions (CE $43.1 \%$ and DBE 15.3\%, P=0.0004) and mass (CE 10.2\% and DBE $8.5 \%, \mathrm{P}=0.5)$. DBE provided the advantage of therapeutic intervention: argon plasma coagulation (33 of 59 DBEs), clipping (two of 59), both argon plasma coagulation and clipping (three of 59), polypectomy (two of 59), tattooing (52 of 59) and biopsies (11 of 59). DBE detected lesions not seen by CE in 21 patients; lesions were treated in 18 patients. However, CE detected 31 lesions not seen by DBE. No major complications occurred with either examination.

CONCLUSION: Overall detection rates for both techniques are similar. Each technique detected lesions not seen by the other. These data suggest that CE and DBE are complementary and that both evaluate obscure GIB more fully than either modality alone.

Key Words: Capsule endoscopy; Double-balloon enteroscopy; Obscure gastrointestinal bleeding

Traditional evaluation of obscure gastrointestinal bleeding 1 (GIB) has been either insensitive (small bowel x-ray, push enteroscopy) (1) or associated with morbidity (intraoperative endoscopy) (2). Accordingly, capsule endoscopy (CE) and double-balloon enteroscopy (DBE) have become rapidly
L'entéroscopie à double ballonnet après une endoscopie capsulaire dans la prise en charge d'un saignement gastro-intestinal occulte : Les résultats d'une démarche combinée

HISTORIQUE : Il n'existe pas de consensus sur la précision relative de l'endoscopie capsulaire (EC) par rapport à l'endoscopie à double ballonnet (EDB) pour explorer un saignement gastro-intestinal (SGI) occulte. L'EC est moins envahissante, mais l'EDB assure un examen plus direct de l'intestin grêle, ce qui permet un échantillonnage tissulaire et une intervention thérapeutique.

OBJECTIFS : Évaluer le rendement et l'issue d'une EDB après une EC chez les patients atteints d'un SGI occulte.

MÉTHODOLOGIE : Lorsque l'EDB est devenu facilement accessible au Center for Therapeutic Endoscopy and Endoscopic Oncology (St. Michael's Hospital, Toronto, Ontario), tous les patients atteints d'un SGI occulte ayant consulté entre décembre 2002 et juin 2007 ont été évalués de la même façon, d'abord par ED, puis par EDB (certains subissant d'autres interventions). Les résultats, les issues négatives et les interventions sont exposés.

RÉSULTATS : Cinquante et un patients ( 25 femmes) d'un âge moyen (fourchette) de 64,1 ans (34 à 83 ans) sont déclarés. Huit patients ont subi une EDB deux fois, pour un total de $59 \mathrm{EDB}$. Quatorze patients souffraient d'un SGI apparent et avaient subi un nombre moyen (fourchette) de 10 (0 à 100) transfusions d'unités de globules rouges. Chez ces 51 patients, les auteurs ont comparé les résultats positifs pour chaque type de lésion : angiodysplasie (EC 64,7\% et EDB $61 \%, \mathrm{P}=0,3$ ), ulcères (EC 19,6 \% et $\mathrm{EDB} 18,6 \%, \mathrm{P}=0,5)$, lésions hémorragiques ( $\mathrm{EC} 43,1 \%$ et $\mathrm{EDB} 15,3 \%$, $\mathrm{P}=0,0004$ ) et masse (EC $10,2 \%$ et $\mathrm{EDB} 8,5 \%, \mathrm{P}=0,5)$. L'EDB s'associait à l'avantage de l'intervention thérapeutique : coagulation plasmatique à l'argon (34 sur $59 \mathrm{EDB}$ ), clip (deux sur 59), coagulation plasmatique à l'argon et clip (trois sur 59), polypectomie (deux sur 59), tatouage (52 sur 59) et biopsies (11 sur 59). L'EDB a permis de déceler des lésions non observées par EC chez 21 patients. Ces lésions ont été traitées chez 18 patients. L'EC a permis de déceler 31 lésions non observées par EDB. Aucune complication majeure ne s'est produite par suite de l'une ou l'autre intervention. CONCLUSION : Les taux globaux de détection de ces deux techniques sont similaires. Chaque technique a permis de déceler des lésions omises détectables par l'autre. Selon ces données, l'EC et l'EDB sont complémentaires et ensemble, elles permettent de mieux évaluer un SGI occulte que si elles sont utilisées seules.

adopted into clinical practice within the past few years. However, the role of these newer tests is as yet poorly defined. Both have been reported to be more accurate than enteroscopy and barium studies of the small bowel, but both have also been described to miss important lesions $(1,3-8)$. Therefore, we

Centre for Therapeutic Endoscopy and Endoscopic Oncology, St Michael's Hospital, University of Toronto, Toronto, Ontario

Correspondence: Dr Patarapong Kamalaporn, Centre for Therapeutic Endoscopy and Endoscopic Oncology, 30 Bond Street, St Michael's

Hospital, Toronto, Ontario M5B 1W8. Telephone 416-864-3092, fax 416-864-5993, e-mail patarakamala@yahoo.com

Received for publication November 7, 2007. Accepted March 4, 2008. 
reviewed the results of both procedures in all our patients with obscure GIB seen in the past five years, performing first CE, then DBE. The present retrospective study describes the yield and outcome of this approach.

\section{Patients}

\section{METHODS}

Data on 195 patients with obscure GIB who were seen at the Centre for Therapeutic Endoscopy and Endoscopic Oncology, St Michael's Hospital (Toronto, Ontario) from December 2002 to June 2007 were reviewed. All patients had undergone esophagogastroduodenoscopy and colonoscopy at least twice. Push enteroscopies, radiological small bowel follow-throughs, computed tomography (CT) scans of the abdomen, Meckel scans, red blood cell scans and angiograms had also been performed in some patients. All procedures were performed after obtaining informed consent from the patients.

\section{Protocol}

Patients with contraindications to CE such as gastrointestinal obstruction, stricture or fistula, cardiac pacemakers, other implanted electromedical devices and swallowing disorders were excluded from the study. In all cases, CE was performed first (because artifacts induced by DBE may have been difficult to interpret by $\mathrm{CE}$ ). After reviewing the $\mathrm{CE}$ studies, one of the following management procedures was performed as soon as possible: DBE once it became available, esophagogastroduodenoscopy, push enteroscopy, colonoscopy or close follow-up. DBEs were performed at a mean interval of 139 days (range 40 to 335 days) after CE. The endoscopists knew the results of $\mathrm{CE}$ at the time of $\mathrm{DBE}$.

\section{CE procedure}

The Given M2A CE system (Given Imaging Ltd, Israel) was used. All patients were instructed to withhold oral iron supplements for five days before the CE procedure to avoid potential interference with the test. The patients underwent bowel preparation with $2 \mathrm{~L}$ to $4 \mathrm{~L}$ of polyethylene glycol solution and fasted overnight, at least $8 \mathrm{~h}$ before the procedure. All equipment was disconnected after $8 \mathrm{~h}$. Images were downloaded and reviewed by two experienced reviewers. The locations of the lesions in the small bowel were determined by small bowel transit time.

\section{DBE}

The Fujinon DBE system (Fuji Photo Optical Incorporated Company, Fujinon Inc, Japan) was used. Antegrade, retrograde or combined antegrade and retrograde DBEs were performed with or without intervention under conscious sedation or general anesthesia. The initial approach (antegrade or retrograde) was decided by location of findings in CE. All patients underwent bowel preparation with $4 \mathrm{~L}$ of polyethylene glycol solution and fasted overnight. The DBE procedures were performed by two endoscopists (who did not interpret the CE findings) and assistants.

The therapeutic interventions performed with DBE were argon plasma coagulation, clipping, snare polypectomies, tattooing (to document the length of small bowel visualized) and biopsies. Patients were observed in the recovery room or stayed overnight, depending on the risk of the therapeutic procedures.

\section{Definitions}

The following criteria were used for assessing and classifying findings of CE and DBE (9):

- angiodysplasia or angioectasia - a flat, red mucosal lesion with visible legs or borders;

- ulcer - an interruption of the mucosa with visible depth;

- polyp - a protuberance into the lumen from the normally flat mucosa;

- bleeding lesion - fresh blood seen but no underlying lesion identified; and

- diverticulum - an outpouching lesion from the normal mucosa.

Indeterminate red spots, defined as pinpoint, faintly red areas less than $5 \mathrm{~mm}$ in diameter are not reported because they were not believed to be of any clinical significance (9).

Positive CEs and DBEs were defined as findings that explained the cause of the obscure GIB.

\section{Statistical analysis}

Results are presented as mean (range) or median (range) for continuous data, and frequency (percentage) for categorical data. The data with normal distributions were compared by Student's paired $t$ test. Categorical data were compared by McNemar's $\chi^{2}$ test. $\mathrm{P}<0.05$ was considered to be statistically significant.

\section{Characteristics of patients}

\section{RESULTS}

One hundred ninety-five patients were reviewed in the present study. Of these, 117 patients had overt GIB and 78 patients had occult GIB. Numerous diagnostic procedures were performed before both of these procedures. These included gastroscopy (100\%), colonoscopy (100\%), push enteroscopy (73.3\%), small bowel study (42.2\%), angiography (8.9\%), CT of the abdomen $(8.9 \%)$, Meckel scan $(4.4 \%)$ and red blood cell scan $(4.4 \%)$.

\section{CE}

The CE procedures were performed successfully in 181 of 202 studies. The capsule did not reach the cecum within $8 \mathrm{~h}$ in 19 patients and did not reach even the small bowel in two patients. The median (range) gastric transit and small bowel transit times were $41.97 \mathrm{~min}$ ( $1 \mathrm{~min}$ to $454 \mathrm{~min}$ ) and $243.7 \mathrm{~min}$ ( $0 \mathrm{~min}$ to $465 \mathrm{~min}$ ), respectively. No retention of the capsule occurred in any of the patients. From 202 studies, CE was positive in 114 patients $(56.4 \%)$. The types of lesions were angiodysplasia $(n=65,32.2 \%)$, ulcer $(n=47,23.3 \%)$, bleeding $(n=64,31.7 \%)$ and mass $(n=12,0.05 \%)$. After the $\mathrm{CE}$ studies were reviewed, patients underwent gastroscopy $(n=17)$, push enteroscopy $(n=41)$, colonoscopy $(n=14)$, DBE $(n=51)$, small bowel resection for mass $(n=4)$, intraoperative enteroscopy $(n=5)$ or follow-up examinations $(n=70)$.

\section{DBE}

Fifty-six patients underwent DBE during these five years. Five patients (six DBEs) were excluded from the study because DBEs were performed without previous CE studies (previous history of small bowel stricture from Crohn's disease [n=1], 
TABLE 1

Demographic data of 51 patients who underwent both capsule endoscopy and double-balloon enteroscopy

\begin{tabular}{lc}
\hline Characteristic & Patients \\
\hline Age, years, mean (range) & $64.1(34-83)$ \\
Male:female & $26: 25$ \\
Type of gastrointestinal bleeding, $\mathrm{n}$ & 14 \\
Overt bleeding & 37 \\
Occult bleeding & \\
Medication used, $\mathrm{n}$ & 15 \\
$\quad$ Nonsteroidal anti-inflammatory drugs & 6 \\
Oral anticoagulant & $96.7(79-115)$ \\
Hemoglobin, g/L, mean (range) & $113.5(96-131)$ \\
Transfusion-dependent group (n=33) & $10(10-100)$ \\
$\quad$ Nontransfusion group (n=18) & \\
Number of blood units transfusion, median (range) & \\
\hline
\end{tabular}

positive CT angiogram [n=2] and history of small bowel angiodysplasias $[\mathrm{n}=2])$. In the remaining 51 patients, antegrade DBE was performed in 30 patients, retrograde in 17, and combined antegrade and retrograde in 12 (total of 59 DBEs), all after CE. The mean duration of DBE was 179.8 min (range $40 \mathrm{~min}$ to $335 \mathrm{~min}$ ). Fluoroscopy was used during more than $95 \%$ of the procedures. Thirty-six procedures were performed under general anesthesia and 23 procedures were performed under conscious sedation (fentanyl and meperidine with midazolam). No significant complication was found with any DBE. Tattoos to mark the maximum length of bowel inspected showed that the entire small bowel was visualized by DBE in only three of the 51 patients.

\section{Outcomes}

The demographic data of the 51 patients who underwent both CE and DBE are summarized in Table 1. A comparison of all diagnostic findings of $\mathrm{CE}$ and $\mathrm{DBE}$ are shown in Table 2. CE and DBE detected positive findings in nearly the same proportion of patients ( $88.2 \%$ versus $86.4 \%$, respectively; $\mathrm{P}=0.5$ ). Angiodysplasias were the most frequent findings for both procedures. They were most commonly found in the jejunum, with a mean of 10.6 lesions (range five to 30 lesions). The only abnormality that was detected more frequently by $\mathrm{CE}$ than by DBE was the bleeding lesion (43.1\% versus $15.3 \%, P=0.0004)$. A stromal tumour in the small bowel of one patient, and celiac disease in another patient were diagnosed by both procedures.

\section{Interventions and benefits of DBE, and follow-up} examinations after DBE

Argon plasma coagulation $(n=33)$, clipping $(n=2)$, both argon plasma coagulation and clipping $(n=3)$, polypectomies $(n=2)$, tattooing $(n=52)$ and biopsies $(n=11)$ were performed with 59 DBEs. Table 3 shows the benefits of DBE over CE. DBE detected more treatable lesions: angiodysplasias $(\mathrm{n}=8$, $15.7 \%)$, ulcers $(n=8,15.7 \%)$, bleeding lesions $(n=1,1.9 \%)$ and small bowel polyps (ileal carcinoid) $(\mathrm{n}=1,1.9 \%)$. DBE also detected two cases of small bowel diverticulum and one case of jejunal varices, which were missed by CE. However,
TABLE 2

Comparison of findings between capsule endoscopy (CE) and double-balloon enteroscopy (DBE)

\begin{tabular}{lccc}
\hline Finding & CE $(\mathbf{n}=\mathbf{5 1})$ & DBE $(\mathbf{n}=\mathbf{5 1})^{\star}$ & $\mathbf{P}$ \\
\hline Positive findings, $\mathrm{n}(\%)$ & $45(88.2)$ & $51(86.4)$ & 0.5 \\
Angiodysplasia, $\mathrm{n}(\%)$ & $33(64.7)$ & $36(61)$ & 0.3 \\
$\quad 2(3.9)$ & $1(1.7)$ & \\
Stomach & $2(3.9)$ & $1(1.7)$ & \\
Jejuodenum & $30(58.8)$ & $23(39)$ & \\
lleum & $12(23.5)$ & $12(20.3)$ & \\
Ascending colon & $1(1.9)$ & $4(6.8)$ & \\
Ulcer, $\mathrm{n}(\%)$ & $10(19.6)$ & $11(18.6)$ & 0.5 \\
Bleeding, $\mathrm{n}(\%)$ & $22(43.1)$ & $9(15.3)$ & 0.0004 \\
Mass, $\mathrm{n}(\%)$ & $6(10.2)$ & $5(8.5)$ & 0.5 \\
\hline
\end{tabular}

${ }^{*} A$ total of 59 DBEs were performed in 51 patients

CE detected lesions that were not confirmed by DBE in 31 patients.

Two patients were referred for surgical removal of a stromal tumour and a carcinoid of the ileum, respectively. Fortynine per cent of patients remained clinically stable, with no further blood transfusions, over six months of follow-up examinations. The rest of the patients still needed blood transfusions, with a median of three units (range two to 10 units) in six months. One patient died within one month from previously documented chronic renal failure.

\section{DISCUSSION}

Although each diagnostic modality has a distinct role, an agreement is emerging that the newer techniques of $\mathrm{CE}$ and DBE are preferable to radiological studies of the small bowel, push enterosocpy and intraoperative enteroscopy in the initial workup of obscure GIB $(1,2)$. Data demonstrating a high diagnostic yield, with minimal risk, are particularly extensive for CE (1-4), most likely because this was introduced before DBE and is both less invasive and less time-consuming. The role of DBE in endoscopically treating small bowel lesions seen by CE is now also becoming well documented $(10,11)$. However, the relative merits of $\mathrm{CE}$ and $\mathrm{DBE}$ in the diagnostic evaluation of obscure GIB have yet to be determined. For example, in a recent study (12), DBE found only one lesion (an arteriovenous malformation) in nine patients with obscure GIB and a negative CE finding. In another report (13), DBE clarified or added a new diagnosis in $20 \%$ of patients with a positive CE finding. In our series, in which DBE was performed in all 51 patients with both positive and negative findings at CE, DBE significantly increased the diagnostic yield above CE (seen by DBE, but not by CE) in 21 of 51 patients. We do not know if repeat $\mathrm{CE}$ would have detected these lesions.

In the 51 patients who underwent both $\mathrm{CE}$ and DBE, the CE yield was higher than that reported by other groups (88.2\%). This may be because abnormalities that were considered insignificant by others were considered significant by us, because of interobserver variability, or because of referral bias - patients were referred to us chiefly for DBE, considered by referring physicians to be a new and potentially hazardous procedure, leading to selection of patients for referral with the most ominous occult GIB. We have no ready explanation for why the 


\section{TABLE 3}

Benefit of double-balloon enteroscopy (DBE) over capsule endoscopy (CE) in the present study

\begin{tabular}{|c|c|c|c|}
\hline Finding & $\begin{array}{l}\text { DBE detected lesions, } \\
\text { seen by } C E, n / N\end{array}$ & DBE intervened lesions, seen by $C E, n / N^{*}$ & DBE detected new lesions, notseen by CE, $n^{*}$ \\
\hline Angiodysplasia & $26 / 33$ & 23/33 (APC, n=22; APC + clipping, $n=1)$ & $\begin{array}{l}8 \text { (APC in duodenum, } n=1 ; A P C \text { in jejunum, } n=5 \\
\text { APC in ileum, } n=1 ; A P C+\text { clipping, } n=1)\end{array}$ \\
\hline Ulcer & $3 / 10$ & $1 / 10$ (biopsy) & 8 (biopsy, $n=2$ ) \\
\hline Bleeding lesion & $6 / 22$ & $6 / 22(A P C, n=3 ;$ clipping, $n=2 ;$ APC + clipping, $n=1)$ & 1 (APC in the ileum) \\
\hline Mass & $5 / 6$ & $3 / 6$ (polypectomy, $n=2 ;$ biopsy, $n=1$ ) & 1 (biopsy in ileum) \\
\hline Abnormal mucosa & $1 / 1$ & $1 / 1$ (biopsy) & - \\
\hline Diverticulum & - & - & 1 in the jejunum; 1 in the ileum; \\
\hline Abnormal vessels & - & - & 1 jejunal varices \\
\hline
\end{tabular}

*Therapeutic interventions performed with DBE are shown in parentheses. APC Argon plasma coagulation; N Number of lesions detected by CE

cecal intubation rate was so high $(\mathrm{n}=50)$ in the group undergoing subsequent $\mathrm{DBE}$, other than selection bias, because the cecal intubation rate for all CE patients was lower $(90 \%, n=181)$.

DBE missed lesions seen by CE in 31 of 51 patients. This may have been because the entire small bowel was visualized with DBE in only $5.5 \%$ of patients $(n=3)$, because the interval between CE and DBE was so long that some CE-detectable lesions resolved or because of interobserver variability. However, the data do emphasize the complementary role of CE and DBE. We also confirm the therapeutic potential of DBE, as reported by others (10-11).

Our follow-up was limited in both duration and knowledge of blood transfusion requirements, because most patients returned to the community after evaluation. However, patients are usually referred again if transfusion requirements do not decrease, so we expect that most patients improved.

The next step in investigating obscure GIB is intraoperative enteroscopy, which is still considered to be the gold standard of small bowel visualization and examination. The sensitivity and specificity of this procedure in patients with obscure GIB have been reported to be $95 \%$ and $75 \%$, respectively, but it is more invasive and complication rates range from $2 \%$ to $41.2 \%$ (14).

CE is indicated for obscure GIB, suspected Crohn's disease, suspected small bowel tumours and surveillance in patients with polyposis syndromes, and suspected or refractory malabsorptive syndromes (eg, celiac disease). The capsule should be used with caution in patients with known or suspected gastrointestinal obstruction, fistulas or suspected motility disorders. Capsule retention has not been reported in normal subjects or those with anatomical variants such as colon or small bowel diverticulosis, but has been described at rates of $1.5 \%$ to $5 \%$ in patients with obscure GIB and suspected Crohn's disease. However, this was not a problem in our study. Retained capsules are usually asymptomatic, but nevertheless usually require surgery or endoscopic removal $(15,16)$.

Previous prospective studies and one meta-analysis report a CE yield of $56 \%$ to $70 \%$ for identification of the source of bleeding in obscure GIB, compared with $24 \%$ to $26 \%$ for push enteroscopy $(1,5,6)$. In Crohn's disease, $\mathrm{CE}$ is shown to be superior to small bowel follow-through, push enteroscopy $(17,18)$ and CT enteroclysis (19). For patients with known or suspected polyposis syndrome, $\mathrm{CE}$ was able to detect more lesions than a small bowel follow-through (20). In experienced readers, CE also provided another modality for identification of small intestinal villous atrophy and other endoscopic findings suggestive of celiac disease (21). The limitations of CE include insufficient air insufflation, local re-examination, rinsing, specimen biopsies and therapeutic interventions.

DBE is a new technique that at least potentially permits examination of the entire small bowel, tissue sampling and therapeutic interventions (such as argon plasma coagulation, clipping, polypectomy, tattooing and dilation). DBE has been reported to have a higher detection rate of small bowel diseases than push enteroscopy (79\% versus $31 \%$, respectively) (7), at least partially because a larger proportion of the small bowel can be visualized when combined antegrade and retrograde DBE are performed. Only a small number of adverse events have been reported $(1 \%)$, such as pancreatitis and bowel perforation $(8,10)$, although none occurred in our series.

\section{CONCLUSIONS}

Among the myriad of reported approaches to finding the cause of obscure GIB (1-13), our data support the use of CE as the first diagnostic study of small bowel disease, followed by DBE - not just for tissue sampling and therapeutic intervention, but also to increase diagnostic yield. The relatively low sensitivity of each diagnostic modality, when used separately, also emphasizes the need for new management strategies for obscure GIB.

CONFLICTS OF INTEREST: Four small-bowel capsules were funded by Southmedic Inc. The double-balloon enteroscope and accessories were partially supported by Fuji Photo Optical Incorporated Company. Both companies support the annual Therapeutic Endoscopy Course directed by the senior author (Norman Marcon).

\section{REFERENCES}

1. Triester SL, Leighton JA, Leontiadis GI, et al. A meta-analysis of the yield of capsule endoscopy compared to other diagnostic modalities in patients with obscure gastrointestinal bleeding. Am J Gastroenterol 2005;100:2407-18.

2. Desa LA, Ohri SK, Hutton KA, Lee H, Spencer J. Role of intraoperative enteroscopy in obscure gastrointestinal bleeding of small bowel origin. Br J Surg 1991;78:192-5

3. Lewis BS, Swain P. Capsule endoscopy in the evaluation of patients with suspected small intestinal bleeding: Results of a pilot study. Gastrointest Endosc 2002;56:349-53.

4. Scapa E, Jacob H, Lewkowicz S, et al. Initial experience of wireless-capsule endoscopy for evaluating occult gastrointestinal bleeding and suspected small bowel pathology. Am J Gastroenterol 2002;97:2776-9. 
5. Adler DG, Knipschield M, Gostout C. A prospective comparison of capsule endoscopy and push enteroscopy in patients with GI bleeding of obscure origin. Gastrointest Endosc 2004:59:492-8.

6. de Leusse A, Vahedi K, Edery J, et al. Capsule endoscopy or push enteroscopy for first-line exploration of obscure gastrointestinal bleeding? Gastroenterology 2007;132:855-62.

7. Matsumoto T, Moriyama T, Esaki M, Nakamura S, Iida M. Performance of antegrade double-balloon enteroscopy: Comparison with push enteroscopy. Gastrointest Endosc 2005;62:392-8.

8. Yamamoto H, Kita H, Sunada K, et al. Clinical outcomes of doubleballoon endoscopy for the diagnosis and treatment of small-intestinal diseases. Clin Gastroenterol Hepatol 2004;2:1010-6.

9. Tang SJ, Christodoulou D, Zanati S, et al. Wireless capsule endoscopy for obscure gastrointestinal bleeding: A single-centre, one-year experience. Can J Gastroenterol 2004;18:559-65.

10. Heine GD, Hadithi M, Groenen MJ, Kuipers EJ, Jacobs MA, Mulder CJ. Double-balloon enteroscopy: Indications, diagnostic yield, and complications in a series of 275 patients with suspected small-bowel disease. Endoscopy 2006;38:42-8.

11. Li XB, Ge ZZ, Dai J, et al. The role of capsule endoscopy combined with double-balloon enteroscopy in diagnosis of small bowel diseases. Chin Med J (Engl) 2007;120:30-5.

12. Hadithi M, Heine GD, Jacobs MA, van Bodegraven AA, Mulder CJ. A prospective study comparing video capsule endoscopy with double-balloon enteroscopy in patients with obscure gastrointestinal bleeding. Am J Gastroenterol 2006;101:52-7. (Erratum in 2006;101:682).

13. Kaffes AJ, Siah C, Koo JH. Clinical outcomes after double-balloon enteroscopy in patients with obscure GI bleeding and a positive capsule endoscopy. Gastrointest Endosc 2007;66:304-9.

14. Hartmann D, Schmidt H, Bolz G, et al. A prospective two-center study comparing wireless capsule endoscopy with intraoperative enteroscopy in patients with obscure GI bleeding. Gastrointest Endosc 2005;61:826-32.

15. Lewis B. How to prevent endoscopic capsule retention. Endoscopy 2005;37:852-6

16. Sears DM, Avots-Avontins A, Culp K, Gavin MW. Frequency and clinical outcome of capsule retention during capsule endoscopy for GI bleeding of obscure origin. Gastrointest Endosc 2004;60:822-7.

17. Mow WS, Lo SK, Targan SR, et al. Initial experience with wireless capsule enteroscopy in the diagnosis and management of inflammatory bowel disease. Clin Gastroenterol Hepatol 2004;2:31-40.

18. Chong AK, Taylor A, Miller A, Hennessy O, Connell W, Desmond P. Capsule endoscopy vs. push enteroscopy and enteroclysis in suspected small-bowel Crohn's disease. Gastrointest Endosc 2005;61:255-61.

19. Voderholzer WA, Beinhoelzl J, Rogalla P, et al. Small bowel involvement in Crohn's disease: A prospective comparison of wireless capsule endoscopy and computed tomography enteroclysis. Gut 2005;54:369-73.

20. Schulmann K, Hollerbach S, Kraus K, et al. Feasibility and diagnostic utility of video capsule endoscopy for the detection of small bowel polyps in patients with hereditary polyposis syndrome. Am J Gastroenterol 2005;100:27-37.

21. Cellier C, Green PH, Collin P, Murray J; ICCE. ICCE consensus for celiac disease. Endoscopy 2005;37:1055-9. 


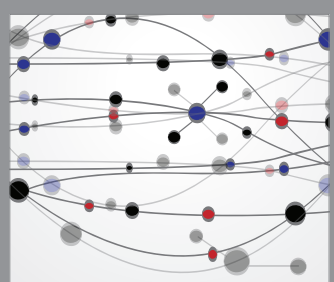

The Scientific World Journal
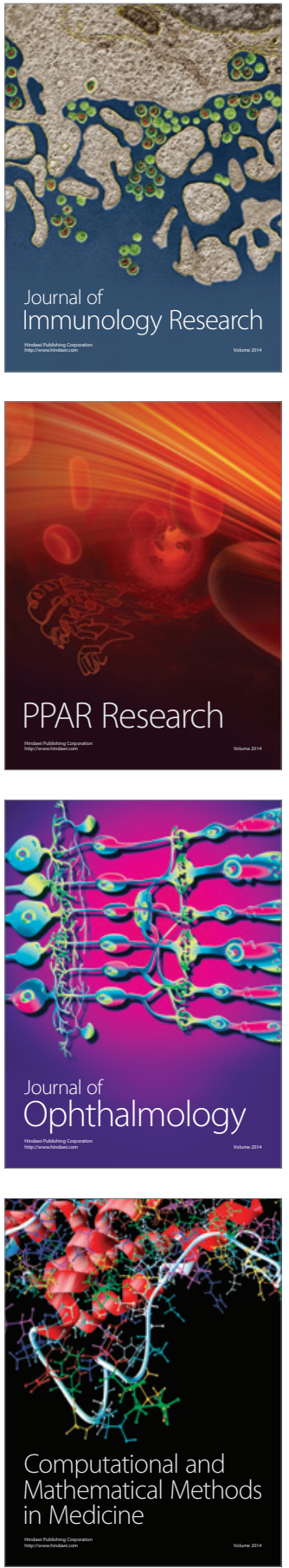

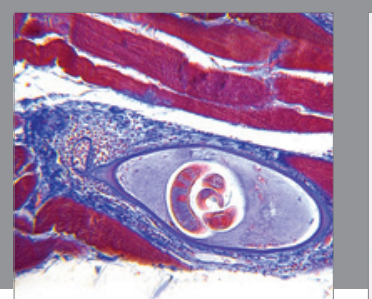

Gastroenterology Research and Practice

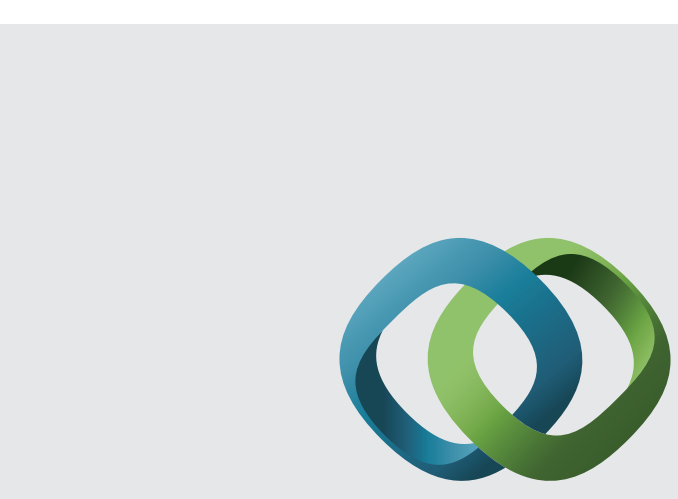

\section{Hindawi}

Submit your manuscripts at

http://www.hindawi.com
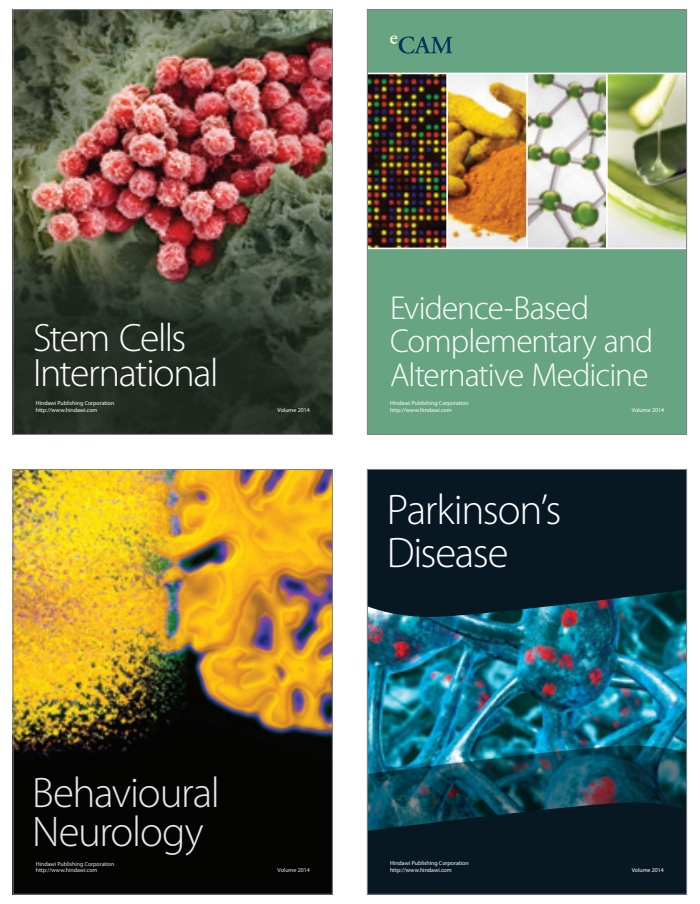
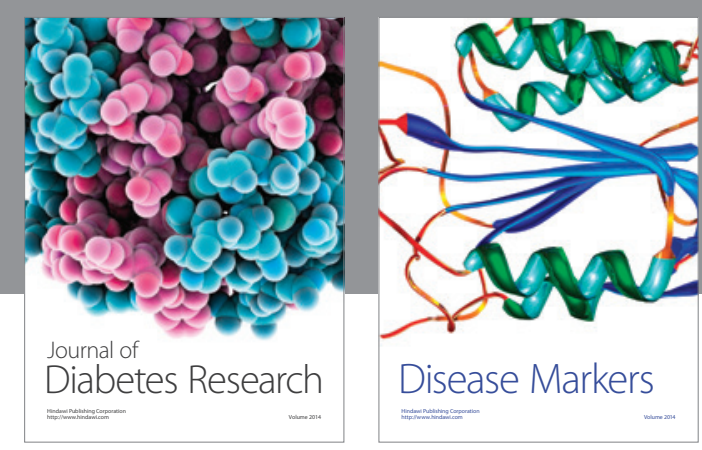

Disease Markers
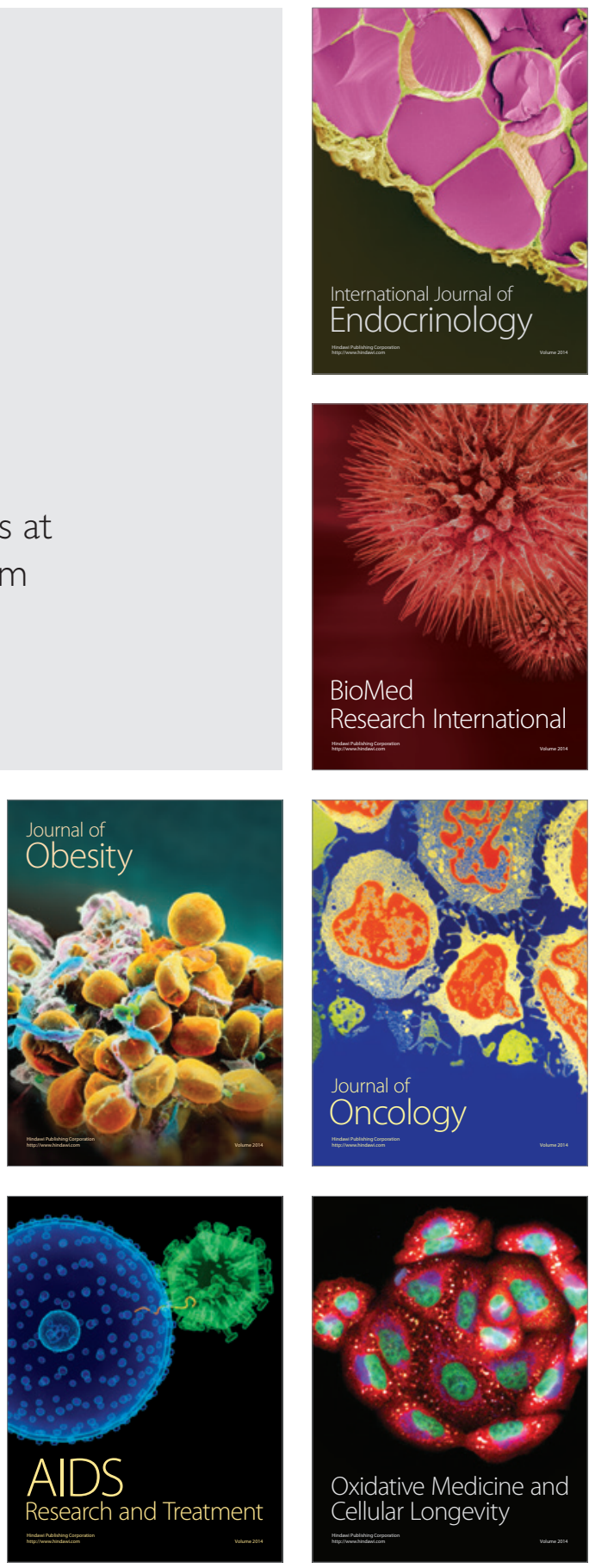